\title{
Detección de micrometástasis por RT-PCR de citokeratina 20 y su correlación con la sobrevida global en pacientes portadores de cáncer colorrectal
}

\author{
Marcelo Garrido S, Pablo Ramírez V, Concepción Risueño Aa, \\ Eric 0 rellana $U$, Héctor Galindo A, Manuel Álvarez $Z$. \\ Cytokeratin 20 as a marker of tumor \\ progression or dissemination \\ in patients with colorectal cancer
}

\begin{abstract}
Background: Colorectal cancer relapses or metastasizes in 30\% of cases. Cytokeratin 20 is present in 95\% of colorectal tumors and their metastases and could be used as a marker to detect tumor cells. Aim: To assess the usefulness and prognostic value of peripheral blood and bone marrow cytokeratin 20 determinations in patients with colorectal cancer. Material and methods: Blood and bone marrow samples were obtained from 56 patients with colorectal cancer aged 26 to 77 years (31 females) before surgical procedure. They were followed for a mean of 22 months (range 2.9 to 72 months) after surgery. Blood and bone marrow from 45 patients without cancer and 35 healthy subjects were used as negative controls. Messenger RNA expression of cytokeratin 20 was studied by real time and nested polymerase chain reaction. Results: Cytokeratin 20 was detected in $6 \%$ of controls and $41 \%$ of patients. There was no relation between cytokeratin 20 expression and age, gender, overall survival, tumor relapse, progression, localization or stage. Conclusions: Cytokeratin 20 determination is not useful as a marker of tumor progression or dissemination in patients with colorectal cancer (Rev Méd Chile 2008; 136: 482-90).
\end{abstract}

(Key w ords: Colonic neoplasms; Keratin-20; Neoplasm metastasis)

Recibido el 14 de mayo, 2007. Aceptado el 14 de diciembre, 2007.

Departamento de Hematología-Oncología, Oncología Médica Centro de Cáncer, Pontificia Universidad Católica de Chile. Santiago de Chile.

${ }^{\mathrm{a} B i o ́ l o g a}$

$\mathrm{E}^{1}$ 1 cáncer colorrectal (CC) es la cuarta causa de muerte por cáncer en el mundo ${ }^{1,2}$, debido a

Correspondencia a: Dr. Manuel Álvarez Z. Centro de Cáncer, Pontificia Universidad Católica de Chile. Diagonal Paraguay 319, Santiago, Chile. Fono: 56-2-3546919. Fax: 56-2-247232. E mail: malvarez@med.puc.cl enfermedad metastásica o a recaída del tumor sometido previamente a cirugía.

La etapificación basada en el examen microscópico del tumor, los ganglios regionales y la determinación de enfermedad metastásica (TNM) son los mejores predictores de sobrevida ${ }^{3,4}$. Sin embargo, a pesar de una adecuada etapificación, aquellos pacientes sometidos a cirugía curativa sin enferme- 
dad ganglionar tienen entre $9 \%$ y $13 \%$ de recurrencia y entre $21 \%$ y $28 \%$ de metástasis a distancia a 5 años ${ }^{5}$, indicando que ellos tienen enfermedad mínima residual después de la cirugía 6 .

La detección de micrometástasis a través de la pesquisa de células tumorales diseminadas en los ganglios linfáticos, sangre periférica (SP) o médula ósea $(\mathrm{MO})^{7}$, mediante inmunohistoquímica (IHQ), puede mejorar la etapificación, contribuir a una mejor predicción del pronóstico ${ }^{8}$ y de esta forma modificar la conducta terapéutica. Sin embargo, la sensibilidad de detección varía dependiendo de la técnica de IHQ y el protocolo utilizado. Por esta razón, el uso de técnicas altamente sensibles basadas en la amplificación por transcripción reversa acoplada a reacción en cadena de polimerasa (RT-PCR) se está utilizando con mayor frecuencia 9 , logrando identificar una célula tumoral en $10^{9}$ células mononucleares ${ }^{10}$.

Para identificar células tumorales colorrectales se ha usado como marcador citoqueratina 20 $(\mathrm{CK} 20)^{11}$, un subtipo de filamento intermedio del citoesqueleto celular que se expresa predominantemente en los tejidos epiteliales (gástrico, intestinal, ureteral y células de Merkel) y cuya expresión se mantiene incluso después de la transformación neoplásica $^{12}$. En el adenocarcinoma de colon 95,6\% de los casos tiene expresión de CK2013.

La relevancia pronóstica de las células tumorales diseminadas detectadas por RT-PCR de CK20 en tumores colorrectales, ha sido descrita por varios grupos de investigadores. Desde que Burchill propuso el uso de CK20 como marcador para detectar células tumorales gastrointestinales circulantes mediante RT-PCR ${ }^{14}$, varios autores han realizado estudios similares, con resultados controversiales: algunos encontraron asociación entre CK20 por RTPCR y el estadio tumoral, grado histológico y recurrencia; otros han reportado que no hay correlación o que su detección no es específica de células tumorales ${ }^{15-25}$. Estas discrepancias en los resultados pueden explicarse debido a la heterogeneidad inter e intratumoral en la expresión proteica y de ARNm de CK20, o bien a la expresión génica de CK20 en células no tumorales ${ }^{26,27}$.

Dado la heterogeneidad de resultados y la importancia de disponer de un marcador pronóstico de sobrevida y recurrencia, desarrollamos este estudio prospectivo en muestras preoperatorias de SP y MO de pacientes con CC, mediante RT-PCR de CK20, para determinar su utilidad como predictor de recurrencia tumoral y $S G$.

\section{PACIENTES Y MÉTODOS}

Pacientes. Fueron incluidos 56 pacientes portadores de CC que ingresaron al Centro de Cáncer de la Pontificia Universidad Católica de Chile entre enero de 1997 y agosto de 1999. Ellos fueron etapificados según la clasificación TNM $5^{\text {a }}$ edición y se obtuvieron muestras de MO y SP previo a la intervención quirúrgica o al inicio de tratamiento con quimioterapia o radioterapia, según correspondiera por la ubicación y estadio del tumor primario. La muestra de MO se obtuvo de la cresta ilíaca póstero-superior y la de SP de la vena del antebrazo, previo consentimiento informado del paciente. El estudio fue aprobado por nuestro comité de ética.

Controles. Como controles negativos se analizaron muestras de MO de pacientes ( $\mathrm{n}=45)$ no oncológicos y SP de donantes sanos $(n=35)$. Como controles positivos se utilizaron muestras de tumores digestivos.

Extracción de ARN total. La fracción de células mononucleadas se obtuvo por centrifugación en gradiente de densidad a través de Lymphoprep (Nycomed Pharma AS, Oslo, Noruega). Las células extraídas de la interfase fueron lavadas con solución buffer fosfato salina (PBS1x) y guardadas a $-20^{\circ} \mathrm{C}$ en guanidina isotiocianato (GTC) hasta su estudio. El ARN total fue extraído de las células por el método de Chomzynsky y Sachiii ${ }^{28}$ y se resuspendió en $35 \mu \mathrm{l}$ de agua libre de RNasas. Su concentración se determinó por espectrofotometría a $260 \mathrm{~nm}$.

Transcripción reversa (RT). 2,0 $\mu \mathrm{g}$ de ARN fueron sometidos a $70^{\circ} \mathrm{C}$ por 10 min e inmediatamente enfriados en hielo. El ADN complementario (cADN) fue sintetizado en $20 \mu \mathrm{l}$ de buffer TR (50 $\mathrm{mM}$ Tris-HCl $\mathrm{pH}=8,0$ ) que contenía $75 \mathrm{mM} \mathrm{KCl}, 10$ $\mathrm{mM}$ DTT, $3 \mathrm{mM} \mathrm{MgCl} 2,2,5 \mu \mathrm{M}$ de partidores hexámeros random, $500 \mu \mathrm{M}$ de cada deoxinucleótido (dNTPs) y $200 \mathrm{U}$ de transcriptasa reversa MMLV (Promega, Madison, WI, USA). La mezcla fue incubada a $20^{\circ} \mathrm{C}$ por $5 \mathrm{~min}, 37^{\circ} \mathrm{C}$ por $60 \mathrm{~min} y$ $94^{\circ} \mathrm{C}$ por $5 \mathrm{~min}$. 
Reacción en cadena de la polimerasa (PCR). $10 \mu \mathrm{l}$ de cADN fueron amplificados en $50 \mu \mathrm{l}$, mediante PCR para CK20 (673 pb) mediante 30 ciclos de $94^{\circ} \mathrm{C}$ por $1 \mathrm{~min}, 65^{\circ} \mathrm{C}$ por $1 \mathrm{~min}$ y $72^{\circ} \mathrm{C}$ por $1 \mathrm{~min}$, seguido de una extensión final de $72^{\circ} \mathrm{C}$ por 10 min, usando los partidores CK-1 y CK-4 (Tabla 2).

Nested PCR o PCR anidado. Para aumentar la sensibilidad y especificidad de la reacción, $1 \mu \mathrm{l}$ de esta amplificación fue sometido a una segunda amplificación en $25 \mu \mathrm{l}$, por PCR anidado para CK20 (317 pb) siguiendo el mismo programa, usando los partidores CK-2 y CK-3 (Tabla 3). Un $\mu l$ de la primera amplificación para CK20 fue amplificado en $25 \mu \mathrm{l}$ por PCR para beta-2-microglobulina (201 pb), con el mismo programa de amplificación que CK20, con los partidores AS-53 y AS-54 (Tabla 2).

Todas las reacciones de amplificación se hicieron en buffer PCR $(50 \mathrm{mM}$ Tris- $\mathrm{HCl} \mathrm{pH}=9)$ que contenía $50 \mathrm{mM} \mathrm{NaCl}, 1,5 \mathrm{mM} \mathrm{MgCl} 2,200 \mu \mathrm{M}$ de cada dNTP, 0,4 $\mu \mathrm{M}$ de cada partidor para CK20 y $0,2 \mu \mathrm{M}$ para beta-2-microglobulina y $1,25 \mathrm{U}$ de Taq ADN polimerasa (Promega, Madison, WI, USA).
La ausencia de contaminación se verificó mediante RT-PCR de controles negativos (todos los reactivos excepto cADN).

Todos los fragmentos amplificados fueron analizados por electroforesis en geles de agarosa al $2 \%$, teñidos con bromuro de etidio. El peso molecular fue determinado por comparación con un marcador de pesos moleculares para ADN, Ladder DNA (Life and Technology).

Estadística. El objetivo primario fue correlacionar el estado de CK20 por RT-PCR, con la sobrevida global (SG) y la sobrevida libre de recurrencia (SLR). Como objetivos secundarios evaluamos la SG de la cohorte, sobrevida según diagnóstico (colon o recto), estadio tumoral y sexo. También se estudió la correlación entre la positividad de CK20 y el lugar de obtención de la muestra (SP o MO) y la probabilidad de recaída tumoral en pacientes con cánceres colorrectales estadios II y III.

El análisis univariado para SG se realizó con las variables edad de diagnóstico, estadio tumoral, estado de CK20 y lugar del primario. Para recaída se analizaron las mismas variables por regresión logística. El análisis multivariado se efectuó por

Tabla 2. Partidores de CK 20 para RT-PCR

\begin{tabular}{|lll|}
\hline CK-1: & 5' CAAATTGAAGAGCTGCGAAGTCAG 3' & (Exon 1) \\
CK-4: & 5' CCATGTTACTCCGAATCTGCATC 3' & (Exon 6) \\
CK-2: & 5' GTCAATGTGGAGGTTGGATGCTG 3' & (Exon 4) \\
CK-3: & 5' CAGAGAGCTCAACAGCGACTG 3' & (Exon 6) \\
\hline
\end{tabular}

Los partidores CK-1 y CK-4 fueron utilizados para RT-PCR inicial y CK-2 y CK-3 para nested PCR.

Tabla 3. Características clínicas, seguimiento y expresión de CK20 de los pacientes incluidos en el estudio

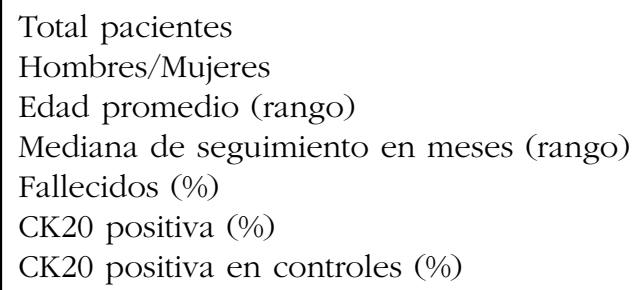

(Exon 1)

(Exon 4) 
modelo de Cox considerando las mismas variables anteriormente mencionadas, en relación a SG y SLR.

Las curvas de sobrevida se realizaron según el método de Kaplan-Meier, y se compararon según el método de Log-rank.

Las comparaciones entre variables categóricas se realizaron por método de chi cuadrado o test exacto de Fisher, con valor p significativo $<0,05$, de dos colas.

\section{Resultados}

Un total de 56 pacientes con diagnóstico de CC se dividieron en las siguientes categorías: estadio II, 8 pacientes; estadio III, 36 pacientes y estadio IV, 12 pacientes. Del total, 21 presentaron cáncer de recto y 35 cáncer de colon; hubo 25 pacientes de sexo masculino y 31 de sexo femenino. El promedio de edad fue de 55 años y la mediana de seguimiento de 22 meses (2,9-72 meses). El ARNm de CK20 fue detectado en 5 controles (6\%) y en 23 pacientes (41\%) (Tabla 3), de los casos CK20 positivos, 3 se encontraban en estadio II, 16 en estadio III y 4 en estadio IV (Tabla 4) (Figura 1).

La SG estimada a 6 años fue de $42 \%$ con 21 pacientes fallecidos por cáncer, no se detectaron diferencias estadísticamente significativas en relación al lugar del primario (colon o recto) $(\mathrm{p}=0,8)$
(Figura 2); lugar de obtención de la muestra (MO o SP) y el estado de citokeratina $20 \quad(\mathrm{p}=0,2)$ (Figura 3). Sólo los distintos estadios tumorales mostraron diferencias en la SG ( $\mathrm{p}=0,001)$ (Figura 4). Sin embargo, al relacionarlo con la positividad para CK20 no se encontró relación estadística entre ellas ( $\mathrm{p}=0,58)$ (Tabla 4).

En el análisis de los subgrupos, los pacientes con estadios II y III (44 pacientes), que corresponden al grupo de pacientes curables por el tratamiento combinado de quimioterapia y cirugía, no demostró diferencias estadísticamente significativas entre la positividad de CK20 y la recurrencia $(\mathrm{p}=0,7)$.

El análisis univariado no mostró influencia de las variables en SG, como tampoco el análisis por

Tabla 4. D istribución de pacientes con cáncer colorrectal por estadio y expresión de CK20

\begin{tabular}{|ccc|}
\hline Estadio (TNM) & $\begin{array}{c}\text { Número de } \\
\text { pacientes }\end{array}$ & $\begin{array}{c}\text { CK20 } \\
\text { positiva }\end{array}$ \\
\hline I & 0 & 0 \\
II & 8 & 3 \\
III & 36 & 16 \\
IV & 12 & 4 \\
\hline
\end{tabular}

$\mathrm{p}=0,58$

\section{$\begin{array}{llllllll}1 & 2 & 3 & 4 & 5 & 6 & 7 & 8\end{array}$}

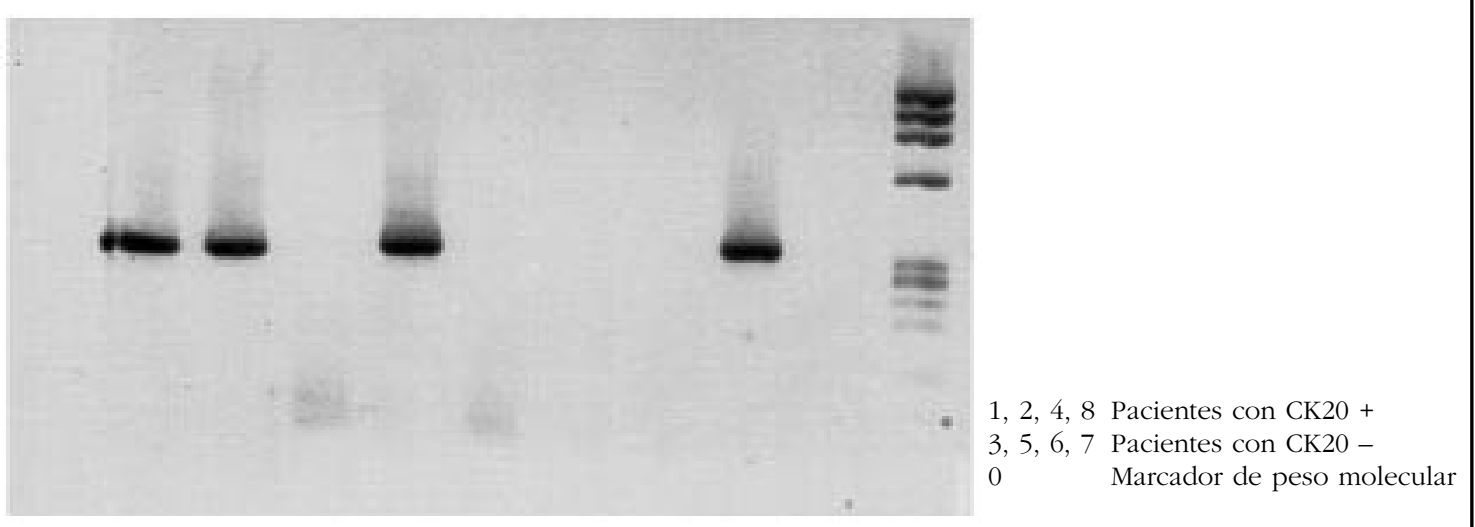

Figura 1. Muestras de sangre periférica de pacientes con cáncer colorrectal sometida a RT-PCR para CK20. 
regresión logística en recaída en el grupo de pacientes con estadio tumoral II y III. El análisis multivariado que incluyó las variables edad, lugar del tumor primario y estado de CK20, para SG y recaída tumoral, no demostró influencia significativa de ninguna de las covariables.

\section{Discusión}

En la última década, el manejo del CC ha experimentado un considerable desarrollo debido a los avances en las técnicas quirúrgicas, prolongación de la sobrevida con esquemas de quimioterapia más activos y aumento en el conocimiento de los cambios moleculares asociados a la carcinogénesis y progresión tumoral. Sin embargo, a pesar de una resección curativa, $21 \%-28 \%$ desarrolla metástasis ${ }^{5}$ lo que hace necesario mejorar la sensibilidad y especificidad de las técnicas de etapificación para detectar pacientes con alto riesgo.

La detección de micrometástasis y factores moleculares o histológicos de mal pronóstico han sido áreas de investigación para conocer los pacientes con mayor riesgo de recaída y muerte $9,10,29,30$.

La detección de micrometástasis a través de la pesquisa de células tumorales diseminadas se ha realizado en ganglios linfáticos, $\mathrm{SP} \mathrm{O} \mathrm{MO}^{7}$, mediante IHQ, IHQ con selección y análisis de imágenes automatizado y técnicas de biología molecular más sensibles y específicas como RT-PCR ${ }^{9,10}$.

Los factores histológicos o moleculares de mal pronóstico son el grado histológico, invasión linfovascular, alta frecuencia de inestabilidad microsatelital (MSI-H), pérdida alélica del cromosoma 18q y alta actividad de timidilato sintetasa. Sin embargo, actualmente se considera que la detección del perfil de activación o inhibición de miles de genes detectados en un chip (microarray) es la forma más exacta para evaluar el riesgo de recurrencia y muerte de los pacientes en muchos tipos de tumores, incluso, en fase de aplicación clínica en cáncer de mama y en $\mathrm{CC}^{29,30}$.

Debido a que la tecnología del microarray es compleja y costosa para su

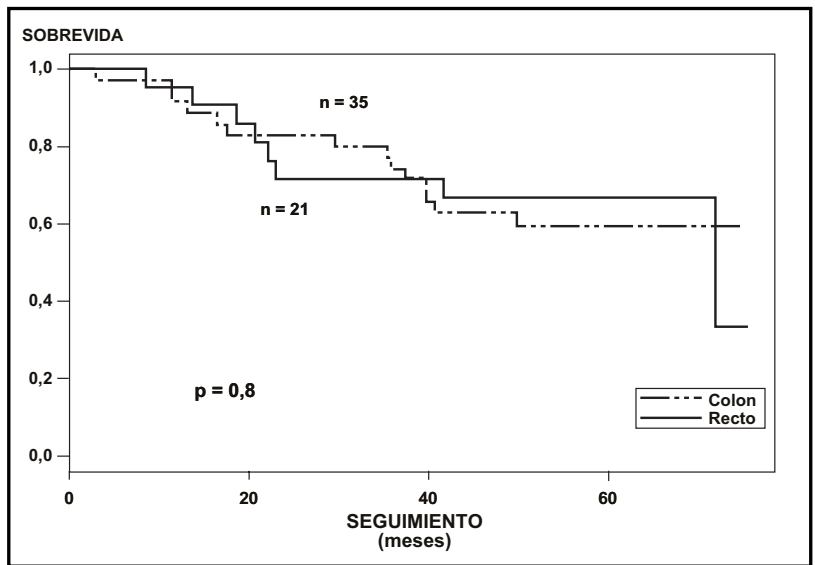

Figura 2. Sobrevida global según lugar del tumor primario, rectal o colónico.

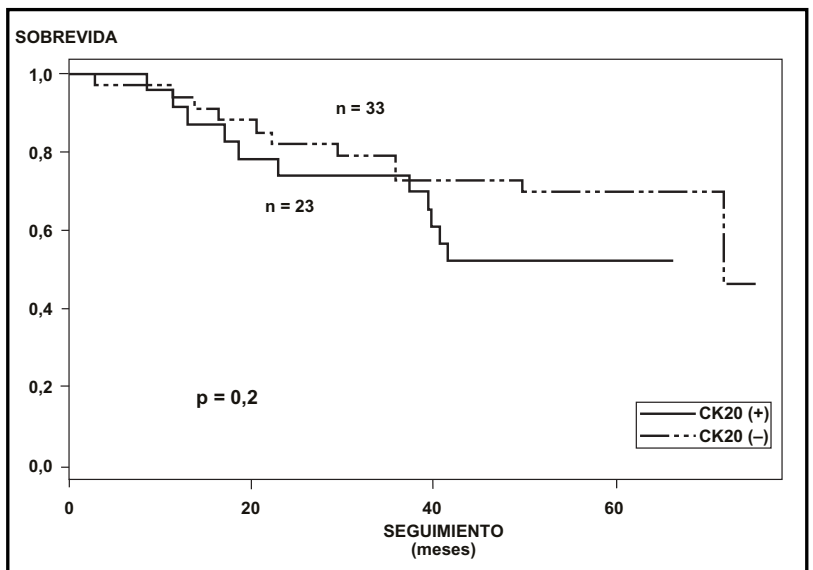

Figura 3. Sobrevida global según expresión de CK20 en pacientes con cáncer colorrectal.

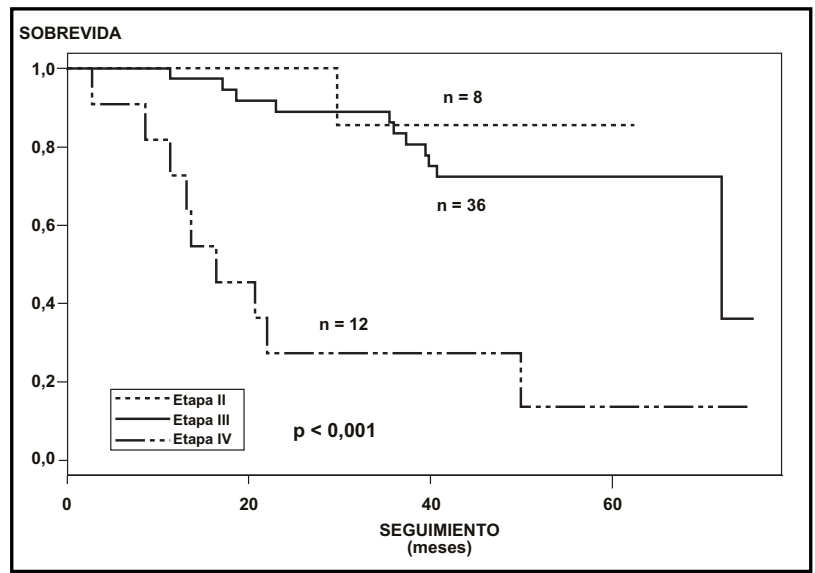

Figura 4. Sobrevida global según estadio en pacientes con cáncer colorrectal. 
aplicación en nuestro medio y a que la detección de citokeratinas por IHQ en MO es un factor pronóstico en otros tumores como cáncer de mama, se evaluó el valor pronóstico de la detección de células tumorales diseminadas a través CK20 en pacientes con CC por RT-PCR y Nested PCR.

En CC la detección de ARNm de CK20 se ha relacionado con un peor pronóstico, ya que su presencia en SP o MO sugiere un mayor avance en el estadio tumoral, mayor número de recurrencias y peor $\mathrm{SG}^{17-19,23,25}$. Sin embargo, otras publicaciones con metodología similar muestran resultados contradictorios ${ }^{20-22,24}$.

En este estudio se mejoró la sensibilidad y especificidad de la técnica de amplificación, complementando al RT-PCR con el uso de nested PCR. Se detectó CK20 en 41\% de los 56 pacientes lo que es concordante con otros estudios que han reportado frecuencias entre $30 \%$ y $47 \% \%^{31-33}$.

En el análisis de subgrupos la detección de CK20 fue de $37,5 \%$ en estadio II, $44,4 \%$ en estadio III y $33,3 \%$ en estadio IV. En los estudios publicados la dispersión de resultados de CK20 positiva por estadio es muy amplia probablemente debido a la selección de pacientes, diferencias en la obtención de las muestras y el uso de distintas técnicas o equipos al realizar RT-PCR (Tabla 1).

Los pacientes con metástasis expresaron CK20 en $33,3 \%$. Wharton ${ }^{34}$ ha descrito que en el 20\%$40 \%$ de los casos no se detecta CK20 por RT-PCR en sangre debido a variaciones en la expresión de ARNm intertumoral, lo que haría variar los niveles de detección entre distintos pacientes. Estudios experimentales de metástasis han demostrado que su circulación ocurre en conglomerados de distintos tamaños lo que puede provocar una variación de muestra a muestra y limitar el valor de la detección; para evitar esto, se ha usado PCR cuantitativo, la detección de 2 marcadores simultáneos (CK20 y antígeno carcinoembrionario), selección inmunomagnética de células epiteliales con posterior PCR cuantitativa de CK20 35 y el uso de múltiples muestras por paciente logrando aumentar el porcentaje de detección a 70\%$80 \% 36,37$. La presencia de inhibidores en algunos tejidos y fluidos, la menor expresión de CK20 en la metástasis y la presencia de clones pobremente diferenciados que no expresan el marcador pueden explicar los falsos negativos ${ }^{38}$.

Los falsos positivos en el grupo control fueron 6\%, lo que contribuyó a disminuir la especificidad del método, el usar nested PCR puede aumentar este porcentaje al aumentar la sensibilidad de la técnica. En otros estudios de CK20 con RT-PCR el porcentaje de falsos positivos oscila entre 5\% y 100\% (Tabla 1). Entre las variables que pueden determinarlo están la contaminación de las muestras con células epidérmicas, transcripción ilegítima de CK20, pseudogenes, las condiciones del termociclador ${ }^{38}$ y la expresión de CK20 en células hematopoyéticas ${ }^{26}$. Al respecto hay evidencia que demuestra una mayor transcripción de ARNm de CK20 en tejidos normales y una menor regulación en tejidos tumorales ${ }^{27}$.

El seguimiento de la cohorte mostró SG y SLR similar a lo reportado en series aleatorizadas, demostrando la efectividad de los tratamientos aplicados. En estadios localizados (estadios II y III) no se logró confirmar el valor predictivo en recurrencia y muerte de CK20. Las posibles explicaciones son: que las células tumorales circulantes detectadas no necesariamente sean responsables del desarrollo de metástasis, que circulen en conglomerados, que sean destruidas por mecanismos inmunológicos ${ }^{39}$, a una variación en la expresión intratumoral de CK20 o a que la técnica empleada tenga tan alta sensibilidad que detecte células que no tengan trascendencia clínica. Al respecto puede plantearse que exista un umbral óptimo de detección. Koch publicó un estudio en 2006 donde incluyó 90 pacientes en etapa II y mostró que CK20 era un predictor independiente de SLR, pero no se analizó $S G^{40}$. En nuestra cohorte el número de pacientes en esta etapa es muy pequeño para hacer un análisis comparativo.

Ya que utilizamos un número considerable de pacientes y controles, depuramos la técnica de toma de muestra, aumentamos la sensibilidad del RT-PCR con el nested PCR y usamos un marcador altamente expresado en CC, podemos plantear que CK20 no sería predictor de recurrencia o muerte en CC. 


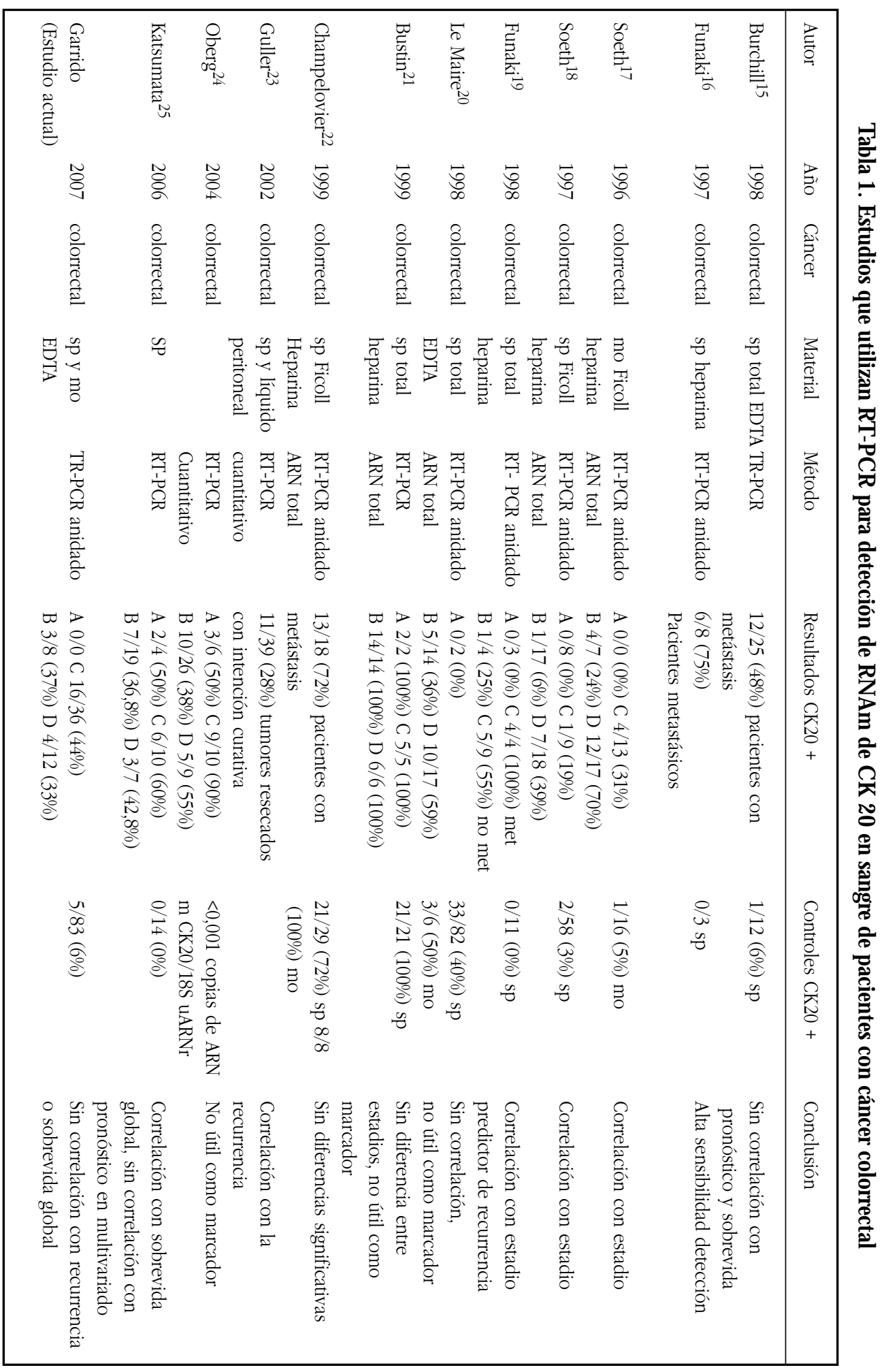




\section{Referencias}

1. Pisani P, Parkin DM, Bray F, Ferlay J. Estimates of the worldwide mortality from 25 cancers in 1990. Int J Cancer 1999; 83: 18-29.

2. Parkin DM, Bray F, Ferlay J, Pisani P. Global cancer statistics, 2002. CA Cancer J Clin 2005; 55: 74-108.

3. Deans GT, Parks TG, Rowlands BJ, Spence Raj. Prognostic factors in colorectal cancer. Br J Surg 1992; 79: 608-13.

4. Compton C, Fenoglio-Preiser CM, Pettigrew N, Fielding LP. American Joint Committee on Cancer Prognostic Factors Consensus Conference: Colorectal Working Group. Cancer 2000; 88: 1739-57.

5. Gunderson ll, Sargent DJ, Tepper Je, Wolmark N, O'Connell MJ, Begovic M et al. Impact of $\mathrm{T}$ and $\mathrm{N}$ stage and treatment on survival and relapse in adjuvant rectal cancer: a pooled analysis. J Clin Oncol 2004; 22: 1785-96.

6. Merrie ae, Yun K, Van Rij AM, McCall JL. Detection and significance of minimal residual disease in colorectal cancer. Histol Histopathol 1999; 14: 561-9.

7. Pantel K, Cote RJ, Fodstad O. Detection and clinical importance of micrometastatic disease. J Natl Cancer Inst 1999; 91: 1113-24.

8. Schlimok G, Funke I, Bock B, Schweiberer B, Witte J, Riethmuller G. Epithelial tumor cells in bone marrow of patients with colorectal cancer: immunocytochemical detection, phenotypic characterization, and prognostic significance. J Clin Oncol 1990; 8: 831-7.

9. Liefers GJ, Tollenaar RA, Cleton-Jansen AM. Molecular detection of minimal residual disease in colorectal and breast cancer. Histopathology 1999; 34: 385-90.

10. Johnson PW, Burchill SA, Selby PJ. The molecular detection of circulating tumour cells. Br J Cancer 1995; 72: 268-76.

11. Litle VR, Warren RS, Moore D $2^{\mathrm{ND}}$, Pallavicini M. Molecular cytogenetic analysis of cytokertain 20labeled cells in primary tumors and bone marrow aspirates from colorectal carcinoma patients. Cancer 1997; 79: 1664-70.

12. Moll R, Zimbelmann R, Goldschmidt MD, Keith M, Laufter J, Kasper M et al. The human gene encoding cytokeratin 20 and its expression during fetal development and in gastrointestinal carcinomas. Differentiation 1993; 53: 75-93.

13. Moll R, Lowë A, Laufer J, Franke W. Cytokeratin 20 in human carcinomas. A new histodiagnostic marker detected by monoclonal antibodies. Am J Pathol 1992; 140: 427-47.

14. Burchill SA, Bradbury MF, Pittman K, Southgate J, Smith B, Selby P. Detection of epithelial cancer cells in peripheral blood by reverse transcriptasepolymerase chain reaction. Br J Cancer 1995; 71 : 278-81.

15. Wyld DK, Selby P, Perren TJ, Jonas SK, Allen-Mersh TG, Wheeldon J ET al. Detection of colorectal cancer cells in peripheral blood by reversetranscriptase polymerase chain reaction for cytokeratin 20. Int J Cancer 1998; 79: 288-93.

16. Funaki NO, Tanaka J, Itami A, Kasamatsu T, Ohshio G, Onodera H ET al. Detection of colorectal carcinoma cells in circulating peripheral blood by reverse transcription-polymerase chain reaction targeting cytokeratin-20 mRNA. Life Sci 1997; 60: 643-52.

17. Soeth E, Roder C, Juhl H, Kruger U, Kremer B, Kalthof $\mathrm{H}$. The detection of disseminated tumor cells in bone marrow from colorectal-cancer patients by a cytokeratin-20-specific nested reverse-transcriptase-polymerase-chain reaction is related to the stage of disease. Int J Cancer 1996; 69: 278-82.

18. Soeth E, Vogel I, Roder C, Juhl H, Marxsen J, Kruger U et al. Comparative analysis of bone marrow and venous blood isolates from gastrointestinal cancer patients for the detection of disseminated tumor cells using reverse transcription PCR. Cancer Res 1997; 57: 3106-10.

19. Funaki nO, Tanaka J, Ohshio G, Onodera H, Maetani S, Imamura M. Cytokeratin 20 mRNA in peripheral venous blood of colorectal carcinoma patients. Br J Cancer 1998; 77: 1327-32.

20. Le Maire V, Sales JP, Wind P, Dumas F, Landi B, FAYEMENDY L ET AL. Evaluation and interest in new molecular markers in colon cancer. Ann Pharm Fr 1998; 56: 9-17.

21. Bustin SA, Gyselman VG, Williams NS, Dorudi S. Detection of cytokeratins 19/20 and guanylyl cyclase $\mathrm{C}$ in peripheral blood of colorectal cancer patients. Br J Cancer 1999; 79: 1813-20.

22. Champelovier P, Mongelard F, Seigneurin D. CK20 gene expression: technical limits for the detection of circulating tumor cells. Anticancer Res 1999; 19: 2073-8.

23. Guller U, Zajac P, Schnider A, Bosch B, Vorburger S, ZuBER M ET AL. Disseminated single tumor cells as detected by real-time quantitative polymerase 
chain reaction represent a prognostic factor in patients undergoing surgery for colorectal cancer. Ann Surg 2002; 236: 768-75.

24. Oberg AN, Lindmark GE, Israelsson AC, Hammarstrom SG, Hammarstrom ML. Detection of occult tumour cells in lymph nodes of colorectal cancer patients using real-time quantitative RT-PCR for CEA and CK20 mRNAS. Int J Cancer 2004; 111: 101-10.

25. Katsumata K, Sumi T, Mori Y, Hisada M, Tsuchida A, AOKI T. Detection and evaluation of epithelial cells in the blood of colon cancer patients using RT-PCR. Int J Clin Oncol 2006; 11: 385-9.

26. Jung R, Petersen K, Kruger W, Wolf M, Wagener C, Zander A et al. Detection of micrometastases by cytokeratin 20 RT-PCR is limited due to stable background transcription in granulocytes. $\mathrm{Br} \mathrm{J}$ Cancer 1999; 81: 870-3.

27. Vlems FA, Diepstra JH, Cornelissen IM, Ruers TJ, Ligtenberg MJ, Punt CJ ET AL. Limitations of cytokeratin 20 RT-PCR to detect disseminated tumour cells in blood and bone marrow of patients with colorectal cancer: expression in controls and downregulation in tumour tissue. Mol Pathol 2002; 55: 156-63.

28. Chomczynski P, SAcchi N. Single-step method of RNA isolation by acid guanidinium thiocyanatephenol-chloroform extraction. Anal Biochem 1987; 162: 156-9.

29. D'Orazio A. Clinical utility of gene microarray for the management of colorectal cancer. Clin Colorectal Cancer 2006; 6: 25-8.

30. Wang Y, Klijn JG, Zhang Y, Sieuwerts AM, Look MP, YANG F ET AL. Gene expression profiles and molecular markers to predict recurrence of Dukes' B colon cancer. J Clin Oncol 2004; 22: 1564-71.

31. Huang P, Wang J, Guo Y, XIE W. Molecular detection of disseminated tumor cells in the peripheral blood in patients with gastrointestinal cancer. J Cancer Res Oncol 2003; 129: 192-8.

32. Vlems FA, Diepstra JH, Punt CJ, Ligtenberg MJ, Cornelissen IM, Van Krieken JH et al. Detection of disseminated tumour cells in blood and bone marrow samples of patients undergoing hepatic resection for metastases of colorectal cancer. $\mathrm{Br} \mathrm{J}$ Surg 2003; 90: 989-95.

33. Bustin SA, Siddiei S, Ahmed S, Hands R, Dorudi S. Quantification of cytokeratin 20, carcinoembryonic antigen and guanylyl cyclase C mRNA levels in lymph nodes may not predict treatment failure in colorectal cancer patients. Int J Cancer 2004; 108: 412-7.

34. Wharton RQ, Jonas SK, Glover C, Khan ZA, Klokouzas A, QuinN H et AL. Increased detection of circulating tumor cells in the blood of colorectal carcinoma patients using two reverse transcription-PCR assays and multiple blood samples. Clin Cancer Res 1999; 5: 4158-63.

35. Guo J, Xiao B, Jin Z, Qin L, Chen J, Chen H et al. Detection of cytokeratin $20 \mathrm{mRNA}$ in the peripheral blood of patients with colorectal cancer by immunomagnetic bead enrichment and real-time reverse transcriptase-polymeras chain reaction. J Gastroenterol Hepatol 2005; 20: 1279-84.

36. Zhang XW, Yang HY, Fan P, Yang L, Chen GY. Detection of micrometastases in peripheral blood by multi-sampling in patients with colorectal cancer. World J Gastroenterol 2005; 11: 436-8.

37. Schuster R, Max N, Mann B, Heufelder K, Thilo F, GRONE J ET AL. Quantitative real-time RT-PCR for detection of disseminated tumor cells in peripheral blood of patients with colorectal cancer using different mRNA markers. Int J Cancer 2004; 108: 219-27.

38. Ghossein RA, Bhattacharya S, Rosai J. Molecular detection of micrometastases and circulating tumor cells in solid tumors. Clin Cancer Res 1999; 5: 1950-60.

39. Sugarbaker PH. Metastatic inefficiency: the scientific basis for resection of liver metastases from colorectal cancer. J Surg Oncol Supp 1993; 3: 158-60.

40. Koch M, Kienle P, Kastrati D, Antolovic D, Schmidt J, Herfarth C et al. Prognostic impact of hematogenous tumor cell dissemination in patients with stageII colorectal cancer. Int J Cancer 2006; 118: 3072-7. 